\title{
INFLUENCE OF SOLUTION PROPERTIES AND GAS ADDITION ON HYDROGEN PEROXIDE PRODUCTION BY A PIN-HOLE BASED PLASMA SOURCE
}

\author{
Z. KozÁKovÁ*, F. KrČMa, A. MožíšovÁ, A. Durrová \\ Faculty of Chemistry, Brno University of Technology, Purkyňova 118, 61200 Brno, Czech Republic \\ * kozakova@fch.vut.cz
}

\begin{abstract}
The paper evaluates concentration of hydrogen peroxide produced by a novel pin-hole plasma source in electrolyte solutions with or without gas addition. An effective production rate of hydrogen peroxide is decreased by the increased argon as well as oxygen flow rate through the plasma region. Further, it is enhanced by higher solution conductivity while it is decreased in the strongly basic conditions with the highest $\mathrm{pH}$ values.
\end{abstract}

Keywords: discharge in liquids, hydrogen peroxide, gas addition, solution properties.

\section{Introduction}

Nowadays there are many different electrode configurations ensuring discharge generation directly in the liquid phase $[1,2]$. A very high electric field value is usually necessary for the initiation of the breakdown. Typical electrode configurations are point to plane [3-5], coaxial [6] or pin-hole systems [7-10]. Especially pin-hole systems are often combined with the additional gas bubbling that extends chemical mechanisms utilised in further applications [11-13]. All discharges in the liquid phase are usually supplied by pulsing high voltage both in the direct current and alternating current regimes up to the microwave excitation region $[14,15]$. This paper presents results obtained by a recently developed electrode system based on the pin-hole discharge configuration without the gas bubbling that was patented in the Czech Republic as well as in the European Union [16-18]. This device has been further modified for the additional gas bubbling through the plasma region [19]. In both electrode modifications (without and with the gas addition), the discharge is generated by DC non-pulsing voltage in various electrolyte solutions giving different $\mathrm{pH}$ values. Thus the previously published detailed characteristics of this plasma source [20] are extended by chemical experiments focused on hydrogen peroxide determination in the dependence on solution properties and gas addition.

\section{Experimental setup}

The electrode system consisted of two electrodes [20]. The main jet electrode (Figure 1) was constructed by a tungsten wire (diameter of $1.0 \mathrm{~mm}$ ) which was inserted into a dielectric cylindrical rod made of Macor ceramics with outer diameter of $10 \mathrm{~mm}$ and with one conical end. An orifice with the diameter of $1.2 \mathrm{~mm}$ was made in the ceramics along its longitudinal axis. A small gap of $1 \mathrm{~mm}$ was kept between the end of the wire electrode and the end of the dielectric rod.
This configuration substantially increased electric field intensity and thus it allowed plasma ignition at relatively low applied voltage (Figure 2). An outer glass tube served as a holder and as a gas inlet. The second electrode was a planar plate made of platinum with dimensions of $20 \times 100 \mathrm{~mm}^{2}$. Concerning the sputtering and lifetime of used electrodes, the main electrode was made of relatively hard ceramics that prolonged the electrode lifetime to hours with any significant sputtering if the positive voltage polarity was applied. Moreover, the tungsten wire inside the ceramic rod was prevented from its erosion by the plasma operation. On the other hand, the plate counter electrode (as the cathode) was much more affecting by the ions and a remarkable sputtering of the plate was visible after tens of hours of plasma operation. Commonly, we used two electrode materials in this plasma system. Aluminium was quite easily sputtered by the discharge, but it had been reported that this element did not decrease the hydrogen peroxide formation a lot [21]. The second electrode material, which we used in experiments presented in this paper, was platinum which was not sputtered so rapidly, but it can serve as a surface catalyser in hydrogen peroxide decomposition [21]. We chose this stable material for comparative measurements supposing that it had the same effect in all experiments.

Both electrodes were immersed in a vessel containing $500 \mathrm{ml}$ of electrolyte solution with initial conductivity of 300,1000 or $15000 \mu \mathrm{S} \mathrm{cm}^{-1}$ (Figure 3). The used electrolyte set the initial $\mathrm{pH}$ of the solution on $5\left(\mathrm{NaH}_{2} \mathrm{PO}_{4}\right), 9\left(\mathrm{Na}_{2} \mathrm{HPO}_{4}\right)$ or $11\left(\mathrm{Na}_{3} \mathrm{PO}_{4}\right)$ and its value remained constant within $3 \%$ during the plasma operation. The change of solution conductivity during the plasma operation depended on the $\mathrm{pH}$. In case of lower $\mathrm{pH}$ (5 and 9), conductivity was stable or slightly increased by no more than $15 \%$ of the initial value during the experiment. In case of strong basic conditions ( $\mathrm{pH} 11$ ), conductivity was even slightly decreased by no more than $10 \%$ of the initial 


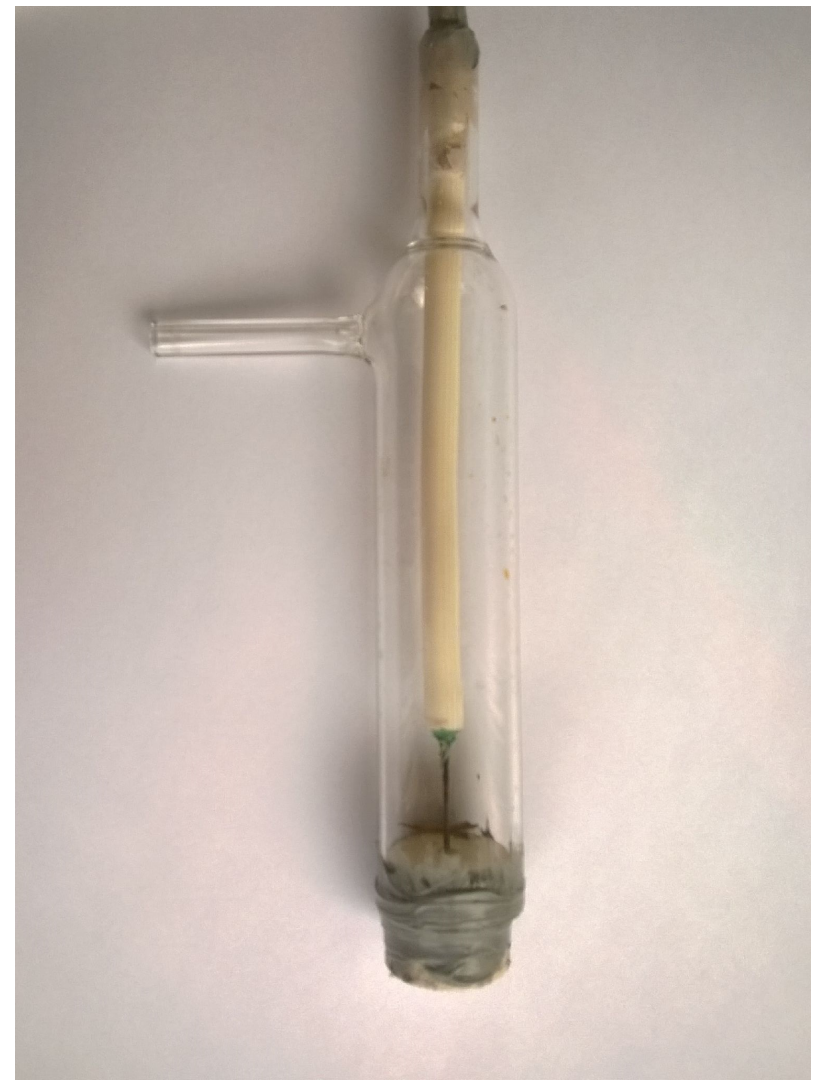

Figure 1. Photo of the jet electrode allowing the gas bubbling through the plasma region.

value. Effects of the gas addition on hydrogen peroxide production were studied for two gases (argon and oxygen) with flow rates in the range of $10-50 \mathrm{ml} \mathrm{min}^{-1}$. For comparison, a set of experiments without the gas bubbling was carried out at the same conditions, too.

The system was supplied by DC non-pulsing high voltage up to $2 \mathrm{kV}$ with the positive polarity on the main electrode. The discharge itself showed selfpulsing operation [20] giving the mean input power from the range of $50-150 \mathrm{~W}$.

Production of chemical active species was represented by hydrogen peroxide formation. Concentration of hydrogen peroxide was determined by a standard colorimetric method using a specific titanium reagent $[20,22]$. Uncertainty of hydrogen peroxide estimation varied from 5 to $10 \%$.

Based on the linear increase of $\mathrm{H}_{2} \mathrm{O}_{2}$ concentration during the initial discharge treatment, an effective production rate $\eta_{\left(\mathrm{H}_{2} \mathrm{O}_{2}\right)}$ in $\mathrm{mg} \mathrm{kJ}^{-1}$ was calculated according to the following equation:

$$
\eta_{\left(\mathrm{H}_{2} \mathrm{O}_{2}\right)}=\frac{a \times M \times V}{P}
$$

where $a$ is the coefficient of the linear dependence of $\mathrm{H}_{2} \mathrm{O}_{2}$ concentration in time (in $\mathrm{mol} \mathrm{L}^{-1} \mathrm{~S}^{-1}$ ), M is the molecular weight of $\mathrm{H}_{2} \mathrm{O}_{2}\left(34 \mathrm{~g} \mathrm{~mol}^{-1}\right), V$ is the treated volume (in $\mathrm{L}$ ) and $P$ is the input power (in W).

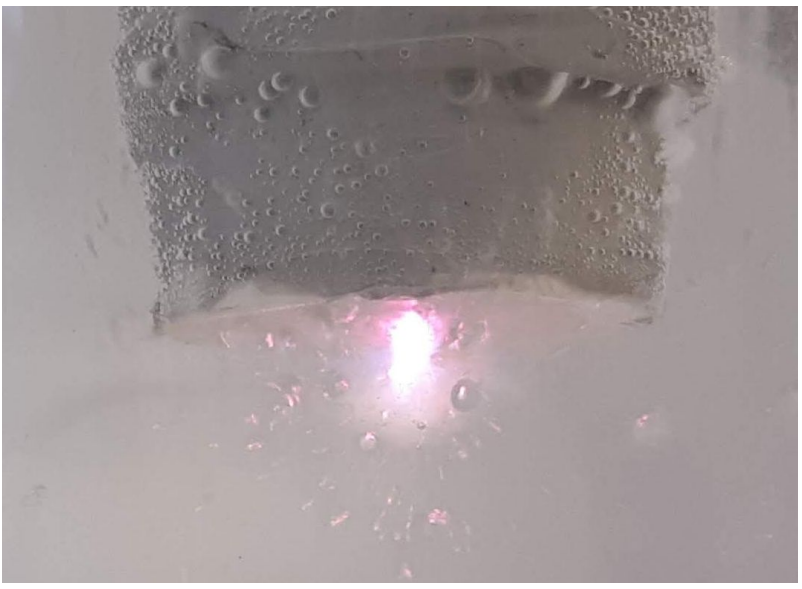

Figure 2. Detailed photo of the active plasma region around the end of the jet electrode (applied power of $50 \mathrm{~W}$ without the gas addition, positive polarity; phosphate solution: $\left.\mathrm{pH} 5,300 \mu \mathrm{Scm}^{-1}\right)$.

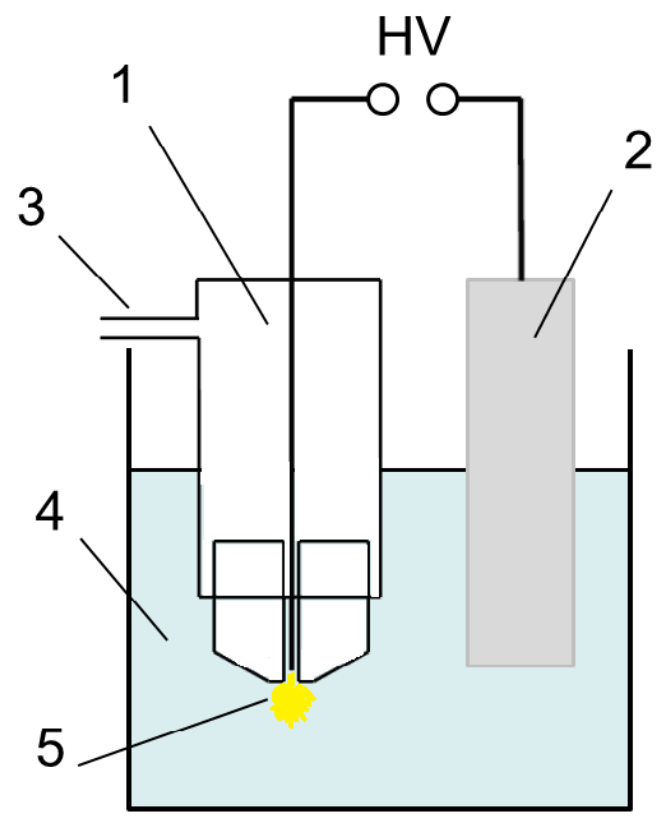

Figure 3. Experimental scheme consisting of both electrodes immersed into the electrolyte solution: 1 - jet electrode, 2 - counter electrode, 3 - gas inlet, 4-glass vessel with electrolyte solution, 5 - active plasma region.

\section{Results}

\subsection{Influence of solution $\mathrm{pH}$ and conductivity}

As the previous results [20] indicated significantly higher production of hydrogen peroxide when positive polarity was applied on the main electrode, presented results are also focused on this configuration. An influence of $\mathrm{pH}$ and solution conductivity set by the chosen electrolyte is demonstrated in Figures 4 and 5 and obtained effective production rates of hydrogen 
peroxide are presented in Table 1 . These results were obtained in the regime without the gas addition.

Concentration of hydrogen peroxide produced during the discharge in the phosphate solution with initial conductivity of $1000 \mu \mathrm{S} \mathrm{cm}^{-1}$ without the additional gas bubbling is compared for acidic ( $\mathrm{pH} 5)$ or basic (pH 9 and 11) conditions (Figure 4). $\mathrm{H}_{2} \mathrm{O}_{2}$ concentrations obtained after the 3-minute plasma treatment are from 0.9 to $1.3 \mathrm{mmoll}^{-1}$. These results are similar to our previous studies carried out in the diaphragm discharge configuration [7] or others in the point to plane pulsed supplied configurations [3]. According to the effective production rate $\eta_{\left(\mathrm{H}_{2} \mathrm{O}_{2}\right)}$, lower $\mathrm{pH}$ values supports $\mathrm{H}_{2} \mathrm{O}_{2}$ formation $\left(\eta_{\left(\mathrm{H}_{2} \mathrm{O}_{2}\right)}=2.4 \mathrm{mg} \mathrm{kJ}^{-1}\right)$ while it is more than twice decreased in strongly basic conditions ( $\left.\mathrm{pH} 11: \eta_{\left(\mathrm{H}_{2} \mathrm{O}_{2}\right)}=0.9 \mathrm{mg} \mathrm{kJ}^{-1}\right)$.

Hydrogen peroxide is formed by several termination reactions taking place during the electric discharge in water $[23,24]$ :

$$
\begin{aligned}
& 2 \cdot \mathrm{OH} \rightarrow \mathrm{H}_{2} \mathrm{O}_{2},\left(k \sim 4 \times 10^{9} \mathrm{dm}^{3} \mathrm{~mol}^{-1} \mathrm{~s}^{-1}\right), \\
& 2 \mathrm{HO}_{2} \cdot \rightarrow \mathrm{H}_{2} \mathrm{O}_{2}+\mathrm{O}_{2},\left(k \sim 2 \times 10^{6} \mathrm{dm}^{3} \mathrm{~mol}^{-1} \mathrm{~s}^{-1}\right), \\
& \mathrm{H} \cdot+\mathrm{HO}_{2} \cdot \rightarrow \mathrm{H}_{2} \mathrm{O}_{2},\left(k \sim 1 \times 10^{10} \mathrm{dm}^{3} \mathrm{~mol}^{-1} \mathrm{~s}^{-1}\right) .
\end{aligned}
$$

Taking into account previous reactions, the most determining factor for hydrogen peroxide formation is the amount of hydroxyl radicals. The main mechanisms of the ground state $\mathrm{OH}(X)$ radical production are dissociation of water molecules by the direct impact of electrons and de-excitation of $\mathrm{OH}(A)$ excited radical by quenching caused by higher contents of water [12]. One of the most effective reactions leading to the formation of excited state $\mathrm{OH}(A)$ is dissociative recombination of water ions [25]:

$$
\begin{aligned}
& \mathrm{H}_{2} \mathrm{O}^{+}\left(\mathrm{H}_{3} \mathrm{O}^{+}\right)+\mathrm{e}^{-} \rightarrow \cdot \mathrm{OH}(A)+\mathrm{H} \cdot \\
& \left(k \sim 10^{-8}-10^{-10} \mathrm{~cm}^{-3} \mathrm{~s}^{-1}\right) .
\end{aligned}
$$

Therefore, formation of water ions $\mathrm{H}_{2} \mathrm{O}^{+}$by the direct electron ionisation and increased concentration of $\mathrm{H}_{3} \mathrm{O}^{+}$ions in acidic solutions stimulate production of $\mathrm{OH}$ radical and subsequent hydrogen peroxide.

Decreasing the initial conductivity of all electrolyte solutions from 1000 to $300 \mathrm{\mu S} \mathrm{cm}^{-1}$, the effective production rate of hydrogen peroxide is almost four times lower (Figure 5). This phenomenon is typical for our pin-hole based plasma system [20], but it is in contrary to previously studied configurations such as the diaphragm discharge [8] or the point to plane electrode geometry [15]. We suppose that a possible explanation of this effect is in a different optimal conductivity for the discharge generation and stability in these systems. While solution conductivity for maximal hydrogen peroxide production is around $400 \mu \mathrm{S} \mathrm{cm}^{-1}$ in the diaphragm [8] or corona [15] systems, its optimum is shifted to higher values in our new pin-hole system. Therefore, the decreasing tendency of hydrogen peroxide production as a function of the solution conductivity would be probably detected at higher values exceeding $1000 \mu \mathrm{S} \mathrm{cm}^{-1}$. However, we have not been focused on a detailed study confirming conductivity effect, yet.

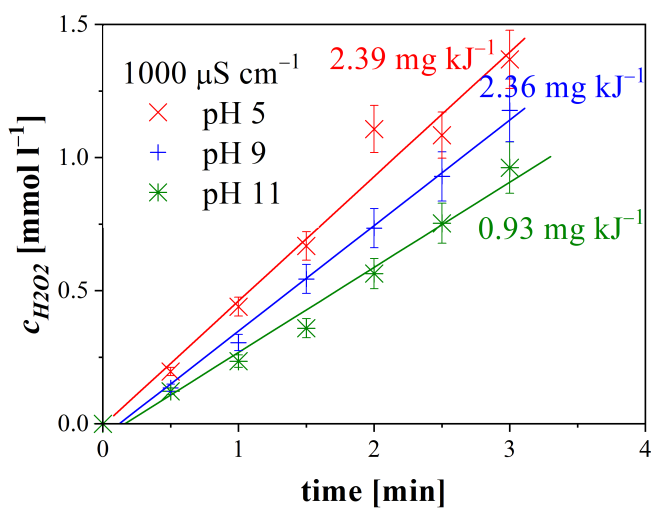

Figure 4. Concentration of hydrogen peroxide during the discharge treatment of electrolyte solutions with different $p H$ and initial solution conductivity of $1000 \mu \mathrm{Scm}^{-1}$.

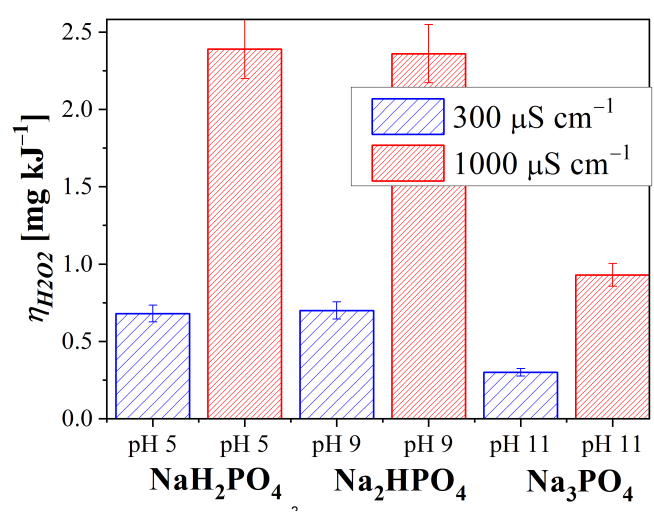

Figure 5. Comparison of $\mathrm{H}_{2} \mathrm{O}_{2}$ effective production rate for different $p H$ and selected initial solution conductivity.

On the other hand, increasing the initial conductivity to $15 \mathrm{mS} \mathrm{cm}^{-1}$, that is similar to the physiological solution, production of hydrogen peroxide is rapidly enhanced at pH 5 and 9 (Table 1). However, a sparse coagulation has been formed by mixing of the used titanium reagent with the samples. Although this coagulation was removed by sedimentation before further analysis, the results for the highest initial conductivity might be involved by this process. There are at least two facts that can influence the relevance of the spectrometric results. Firstly, some hydrogen peroxide might have been adsorbed on the coagulation and therefore, coagulation removal can cause a decrease of the final hydrogen peroxide concentration. On the other hand, some coagulation might have remained in the determined sample and thus, hydrogen peroxide concentration estimated from absorption of the solution could be increased. Therefore, we consider this data as irrelevant and subsequent experiments with the additional gas bubbling were performed only with the lower initial conductivity of 300 and $1000 \mu \mathrm{S} \mathrm{cm}^{-1}$. 


\begin{tabular}{lcll}
\hline \hline Electrolyte & $\mathbf{p H}$ & $\begin{array}{l}\text { Conductivity } \\
{\left[\mu \mathrm{S} \mathrm{cm}^{-1}\right]}\end{array}$ & $\begin{array}{l}\eta_{(\mathrm{H} 2 \mathrm{O} 2)} \\
{\left[\mathrm{mg} \mathrm{kJ}^{-1}\right]}\end{array}$ \\
\hline $\mathrm{NaH}_{2} \mathrm{PO}_{4}$ & 5 & 300 & $1.68 \pm 0.08$ \\
& & 1000 & $2.39 \pm 0.12$ \\
& & 15000 & $6.70 \pm 0.70^{*}$ \\
$\mathrm{Na}_{2} \mathrm{HPO}_{4}$ & 9 & 300 & $1.45 \pm 0.07$ \\
& & 1000 & $2.36 \pm 0.12$ \\
& & 15000 & $7.00 \pm 0.70^{*}$ \\
$\mathrm{Na}_{3} \mathrm{PO}_{4}$ & \multirow{2}{*}{11} & 300 & $0.30 \pm 0.02$ \\
& & 1000 & $0.93 \pm 0.05$ \\
& & 15000 & $0.08 \pm 0.01^{*}$ \\
\hline \hline
\end{tabular}

Table 1. $\mathrm{H}_{2} \mathrm{O}_{2}$ effective production rate for different $\mathrm{pH}$ and initial solution conductivity. (* coagulation)

\subsection{Influence of gas addition}

An influence of the gas addition into the plasma region is demonstrated in Figures 6, 7 and 8. It is obvious that hydrogen peroxide effective production rate is significantly decreased by the added gas although even the smallest flow rate of $10 \mathrm{ml} \mathrm{min}^{-1}$ is used and it is further decreasing by the increasing flow rate independently on the gas quality (Figure 6). Comparing both studied gases, argon as an inert gas and oxygen as a reactive gas, the influence of their addition into the system is similar for $\mathrm{pH} 5$ and 9 (Figures 6 and 8). Both of them substantially decrease the $\mathrm{H}_{2} \mathrm{O}_{2}$ effective production rate and this decrease is higher at the acidic conditions ( $\mathrm{pH} 5$ ). At the highest basic $\mathrm{pH}$ of 11 (Figure 7), final production of hydrogen peroxide is influenced only slightly by the presence of oxygen while there is a remarkable decrease of the hydrogen peroxide effective production rate in case of argon. However, production of hydrogen peroxide is much lower at this $\mathrm{pH}$ even without any gas addition.

An explanation of the negative influence of the gas addition on the hydrogen peroxide formation could be an irregular discharge operation due to the presence of gas bubbles in the plasma region. This instability requires higher energy consumption to maintain the discharge in operation and thus, the effective production rate of hydrogen peroxide is decreased. Moreover, this phenomenon also decreases the possibility of particles collisions in the liquid phase. Especially, collisions between active species such as radicals are important for the hydrogen peroxide formation. Similar problems and decreased production rates were observed also in other underwater systems, especially for helium $[12,13]$.

In our system, we have obtained $\mathrm{H}_{2} \mathrm{O}_{2}$ effective production rates above $2.2 \mathrm{mg} \mathrm{kJ}^{-1}$ without the gas bubbling and decreased values of $0.8 \mathrm{mg} \mathrm{kJ}^{-1}$ in basic (pH 9 and 11) and even lower than $0.5 \mathrm{mg} \mathrm{kJ}^{-1}$ in acidic ( $\mathrm{pH} 5$ ) solutions bubbled with argon. In the mentioned underwater system [12], the highest efficiency of $\mathrm{H}_{2} \mathrm{O}_{2}$ production is reported for air plasma $\left(0.82 \mathrm{mg} \mathrm{kJ}^{-1}\right)$ and it is further decreased in nitrogen $\left(0.65 \mathrm{mg} \mathrm{kJ}^{-1}\right)$, argon $\left(0.53 \mathrm{mg} \mathrm{kJ}^{-1}\right)$ and he- $\operatorname{lium}\left(0.41 \mathrm{mg} \mathrm{kJ}^{-1}\right)$.

Comparing our plasma system generating the discharge directly in the solution to other systems, e.g. using the plasma only in contact with liquids, we obtained quite satisfying results. While we produced 1-1.4 mM concentration of hydrogen peroxide by the 3-minute treatment of $500 \mathrm{ml}$ phosphate solution without any gas bubbling and $0.6-0.8 \mathrm{mM}$ with argon or oxygen addition, hydrogen peroxide concentrations reported in other systems were lower. For example, hydrogen peroxide concentration of $0.4 \mathrm{mM}$ was achieved by the electrospray spark discharge applied on $2.5 \mathrm{ml}$ of buffer phosphate solution for 5 minutes [26]. Even lower hydrogen peroxide concentration of $0.2 \mathrm{mM}$ was obtained by the pulsed DC discharge above the buffer phosphate solution of $900 \mathrm{ml}$ after 30 minutes [27].

Although the mechanisms of $\mathrm{OH}(A)$ radical formation is supplemented by dissociative excitation of water molecules with argon metastables [12]:

$\mathrm{H}_{2} \mathrm{O}+\mathrm{Ar}^{*} \rightarrow \mathrm{Ar}+\cdot \mathrm{OH}(A)+\mathrm{H} \cdot$,

it does not seem sufficient to enhance final production of hydrogen peroxide.

Concerning oxygen addition, interaction of oxygen molecules with plasma might lead to the formation of ozone. Subsequently, ozone rapidly reacted with hydrogen peroxide causing its significant decomposition, especially at higher $\mathrm{pH}[28]$.

\section{Conclusions}

Hydrogen peroxide is formed by our novel pin-hole based plasma source in electrolyte solutions with different $\mathrm{pH}$ values and initial conductivities. The effective production rate of hydrogen peroxide reaches values of about $2.4 \mathrm{mgkJ}^{-1}\left(\mathrm{NaH}_{2} \mathrm{PO}_{4}\right.$ electrolyte, $\mathrm{pH} 5,1000 \mathrm{\mu S} \mathrm{cm}^{-1}$ ) and it is significantly decreased by the increasing $\mathrm{pH}$ value as well as by the decreasing solution conductivity. Especially the effect of solution conductivity is substantially different in our plasma source comparing to other electrode systems. Addition of gas flowing through the plasma region significantly decreases the $\mathrm{H}_{2} \mathrm{O}_{2}$ effective production rate no matter which gas, inert argon or reactive oxygen, is used. 


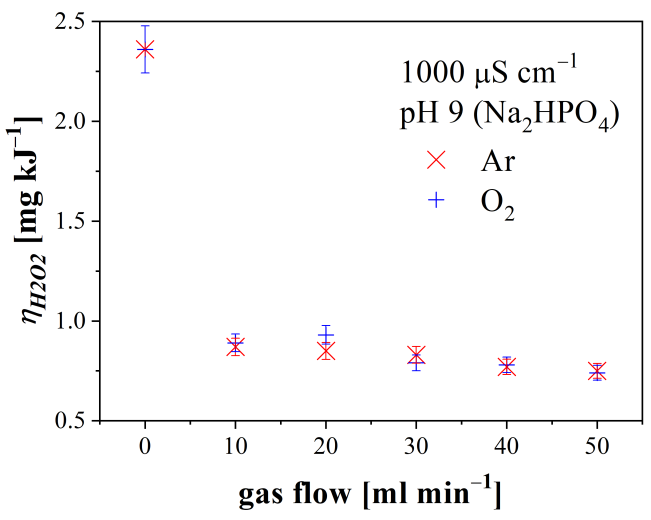

Figure 6. Influence of argon and oxygen flow rate on the $\mathrm{H}_{2} \mathrm{O}_{2}$ effective production rate in $\mathrm{Na}_{2} \mathrm{HPO}_{4}$ solution ( $\mathrm{pH}$ ) ).

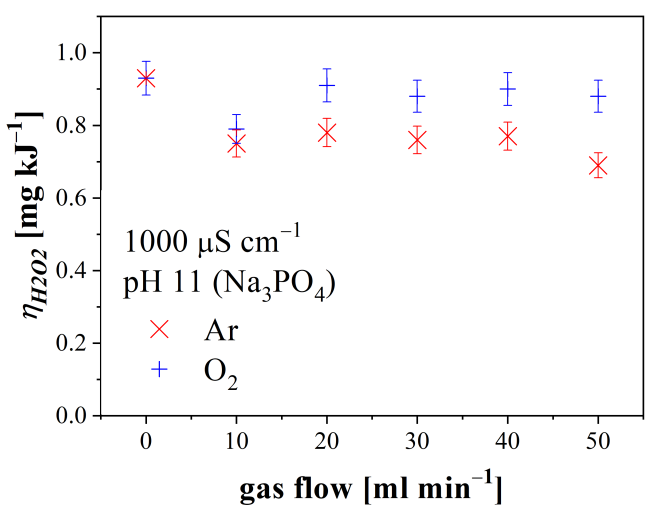

Figure 7. Influence of argon and oxygen flow rate on the $\mathrm{H}_{2} \mathrm{O}_{2}$ effective production rate in $\mathrm{Na}_{3} \mathrm{PO}_{4}$ solution (pH 11).

\section{Acknowledgements}

This work was supported by the Czech Ministry of Education, Youth and Sports, project No. LD14014, and under the frame of COST Action TD1208.

\section{References}

[1] P. J. Bruggemann et al. Plasma-liquid interactions: A review and roadmap. Plasma Sources Sci. Technol., 25, 2016. doi:10.1088/0963-0252/25/5/053002.

[2] S. Samukawa et al. The 2012 plasma roadmap. J. Phys. D Appl. Phys., 45, 2012. doi:10.1088/0022-3727/45/25/253001.

[3] M. J. Kirkpatrick and B. R. Locke. Effects of platinum electrode on hydrogen, oxygen, and hydrogen peroxide formation in aqueous phase pulsed corona electrical discharge. Ind. Eng. Chem. Res., 45(6):2138-2142, 2006. doi:10.1021/ie0511480.

[4] Ruma and et al. Effects of pulse frequency of input power on the physical and chemical properties of pulsed streamer discharge plasmas in water. J. Phys. D: Appl. Phys., 46(12), 2013.

doi:10.1088/0022-3727/46/12/125202.

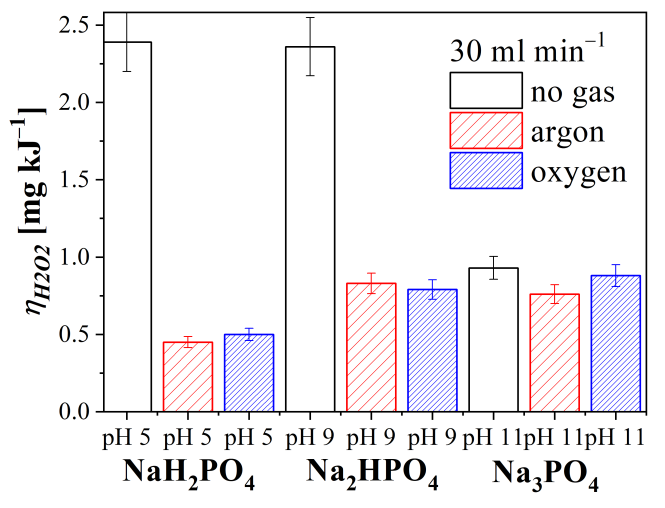

Figure 8. Comparison of $\mathrm{H}_{2} \mathrm{O}_{2}$ effective production rate for different gas addition and $\mathrm{pH}$.

[5] E. Njatawidjaja et al. Decoloration of electrostatically atomized organic dye by the pulsed streamer corona discharge. J. Electrostatics, 63:353-359, 2005.

[6] P. Šunka et al. Potential applications of pulse electrical discharges in water. Acta Physica Slovaca, 54(2):135-145, 2005.

[7] Z. Stará and F. Krčma. Degradation of organic dyes versus $\mathrm{H}_{2} \mathrm{O}_{2}$ generation during the dc diaphragm discharge treatment in water solutions. Acta Physica Slovaca, 55(6):515-519, 2005.

[8] F. Krčma and Z. Stará. Hydrogen peroxide generation in quasi-pulsed discharge in water. Proceedings of ECAMPIG XVI, Grenoble, pages 47-48, 2002.

[9] Z. Kozakova et al. Comparison of liquid and liquid-gas phase plasma reactors for discoloration of azo dyes: Analysis of degradation products. Plasma Process Polym., 15, 2018. doi:10.1002/ppap. 201700178.

[10] F. De Baerdemaeker et al. Characteristics of ac capillary discharge produced in electrically conductive water solution. Plasma Sources Sci. Technol., 16:341-354, 2007.

[11] P. Lukes et al. High power dc diaphragm discharge excited in a vapor bubble for the treatment of water. Plasma Chem. Plasma Process., 33(1):83-95, 2013.

[12] A. Y. Nikiforov et al. Physical properties and chemical efficiency of an underwater dc discharge generated in He, $\mathrm{Ar}, \mathrm{N}_{2}$ and air bubbles. Plasma Sources Sci. Technol., 20, 2011. doi:10.1088/0963-0252/20/3/034008.

[13] L. Němcová et al. Chemical efficiency of $\mathrm{H}_{2} \mathrm{O}_{2}$ production and decomposition of organic compounds under action of dc underwater discharge in gas bubbles. IEEE Trans. Plasma Sci., 39(3):865-870, 2011.

[14] B. R. Locke et al. Electrohydraulic discharge and nonthermal plasma for water treatment. Ind. Eng. Chem. Res., 45(3):882-905, 2006. doi:10.1021/ie050981u.

[15] P. Lukeš. Water treatment by pulsed streamer corona discharge; PhD Thesis. Institute of Plasma Physics, Prague, 2001.

[16] F. Krčma. Jet system for plasma generation in liquids. Czech Republic Patent CZ305304B6, 2015. 
[17] F. Krčma. Jet system for plasma generation in liquids. European Patent EP3122161B1, 2019.

[18] F. Krčma. Jet system for plasma generation in liquids. Protected construction CZ27173, 2015.

[19] F. Krčma. Jet system for plasma generation in gaseous bubbles in liquids. Protected construction CZ30097, 2016.

[20] F. Krčma et al. Characterization of novel pin-hole based plasma source for generation of discharge in liquids supplied by DC non-pulsing voltage. Plasma Sources Sci. Technol., 27, 2018. doi:10.1088/1361-6595/aac521.

[21] E. Vyhnánková et al. Influence of electrode material on hydrogen peroxide generation by DC pinhole discharge. Open Chem., 13:218-223, 2015. doi:10.1515/chem-2015-0054.

[22] G. M. Eisenberg. Colorimetric determination of hydrogen peroxide. Ind. Eng. Chem., Anal. Ed., 15:327-328, 1943

[23] A. A. Joshi et al. Formation of hydroxyl radicals, hydrogen peroxide and aqueous electrons by pulsed streamer corona discharge in aqueous solution. $J$. Hazard. Mater., 41(1):3-30, 1995.

[24] J. L. Magee and A. Chatterjee. Theoretical aspects of radiation chemistry. In Radiation Chemistry: Principles and Applications. VCH Publishers, New York, 1987.
[25] P. Bruggeman et al. Electronic quenching of $\mathrm{OH}(A)$ by water in atmospheric pressure plasmas and its influence on the gas temperature determination by $\mathrm{OH}(A-X)$ emission. Plasma Sources Sci. Technol., 19, 2010. doi:10.1088/0963-0252/19/1/015016.

[26] Z. Machala et al. Formation of ROS and RNS in water electro-sprayed through transient spark discharge in air and their bactericidal effects. Plasma Process. Polym., 10:649-659, 2013. doi:doi:0.1002/ppap. 201200113.

[27] P. Lukes et al. Aqueous-phase chemistry and bactericidal effects from an air discharge plasma in contact with water: evidence for the formation of peroxynitrite through a pseudo-second-order post-discharge reaction of $\mathrm{H}_{2} \mathrm{O}_{2}$ and $\mathrm{HNO}_{2}$. Plasma Sources Sci. Technol., 23, 2014. doi:10.1088/0963-0252/23/1/015019.

[28] C. Bradu et al. Degradation of the chlorophenoxyacetic herbicide 2,4-D by plasmaozonation system. J. Hazard. Mater., 336:52-56, 2017. doi:dx.doi.org/10.1016/j.jhazmat.2017.04.050. 